\title{
Orientación educativa: ¿Cómo lograr un proceso exitoso?
}

\author{
Educational orientation: How to achieve a successful process?
}

DOI: $10.33539 /$ consensus.2019.v24n1.2242

Natalia Guzmán Zegarra ${ }^{1}$

\section{RESUMEN}

El objetivo del presente artículo es hacer una revisión teórica sobre la orientación educativa: la evolución de sus definiciones, sus campos de acción, cómo se lleva a cabo en nuestros tiempos y cuál es su relevancia. Dicha revisión bibliográfica tiene por objetivo recabar los principales ejes teóricos de la orientación educativa, con la finalidad de conocer el impacto de esta variable en la vida de las personas.

\section{Palabras clave}

Orientación educativa, educación, orientador educativo, orientados adolescentes.

\section{ABSTRACT}

The objective of the present article is to make a theoretical review of the educational orientation: the evolution of its definitions, its fields of action, how it is conducted in our times and what its relevance is. This bibliographic review aims to gather the main theoretical axes of educational orientation, in order to know the impact of this variable on people's lives.

\section{Keywords}

Educational orientation, education, educational advisor, oriented adolescents.

\section{INTRODUCCIÓN}

El objetivo de aprender es que el alumno desarrolle su capacidad de pensar, es decir, que lo que reciba del maestro puede serle útil, aún luego de terminado el curso. Los principios del aprendizaje hablan precisamente de eso: de la búsqueda de un sentido, de un propósito, de un fin que contribuya al logro de metas personales, las mismas que se irán trazando en la medida que el estudiante elabore sus propios pensamientos, se nutra de conocimientos y tenga claros los objetivos que quiere para sí mismo.

Es gracias a esta nueva concepción que se tiene del aprendizaje, que logramos posicionar al estudiante en un rol protagónico, un rol que lo empodera y le brinda mayor responsabilidad sobre su propio proceso. Gracias a la guía y el apoyo brindado por el docente y el orientador educativo, el alumno incorporará los conocimientos como parte de sí mismo y así, logrará una participación activa y comprometida con aquello que recibe en las aulas de clase de parte de compañeros y maestros.

Si bien la educación en nuestro país -hoy más que en otros tiempos- cuenta con la mirada de entidades, instituciones públicas y la población en general, todavía quedan aspectos por mejorar y perspectivas por ampliar.

En el 2007, Tonucci, quien ha podido apreciar de cerca las propuestas educativas latinoamericanas y europeas, plantea que la orientación educativa está orientada a desarrollar la autonomía en las personas, pues su propósito esencial resulta ser el reconocimiento de las habilidades, gustos, capacidades, talentos y anhelos, para así, desarrollarlos al máximo en el ámbito que prefieran.

1 Licenciada en Psicología. Terapeuta familiar. Egresada de la maestría en Psicología por la Universidad Femenina del Sagrado Corazón. Candidata al doctorado en Psicología por la Universidad Femenina del Sagrado Corazón, UNIFÉ, Lima. 
Complementando aquello, cabe destacar también que la orientación es un proceso transversal a la vida de las personas, pues el objetivo es que las acompañe desde su ingreso al mundo educativo y así, en su proceso evolutivo, dentro de las dimensiones cognitiva, social y afectiva.

Por su parte, Trahtemberg (2014) sostiene que, la educación y el evaluarla resultan ser aspectos sumamente complejos, lo que trae consigo, demandas crecientes de parte de la sociedad. Demandas tales como: que el estudiante sepa leer, analizar, reflexionar, decidir, crear, manejar ciencias y letras, con una constante apertura a nuevos aprendizajes.

Lo real es que tales competencias no pueden vislumbrarse -al menos no con el ahínco que muchas veces se reclama- en el corto plazo lo que, a su vez, genera que quienes laboran insertos en la comunidad educativa (docentes, orientadores educativos, tutores, directivos, entre otros) no cuenten con un respaldo sostenido por parte de quienes aguardan resultados.

En tal sentido, puede resultar complejo cumplir con lo propuesto -lograr alumnos con autonomía en el plano educativo y personal- si se tiene la sensación de no sentirse un profesional valorado, esto evidenciado en los ingresos económicos que se recibe y la constante crítica que se les lanza, como si fueran los únicos responsables de los tropiezos en pos de una mejor educación para nuestra sociedad.

Así también, corresponde hacer hincapié en la necesidad de que la orientación educativa requiere ser continua para ser efectiva: solo existirá una oportunidad real para los estudiantes, en la medida en la que los orientadores y ellos traben un vínculo sostenido en el tiempo, en el cual se busque aproximarse de cerca a los intereses y habilidades, a fin de desarrollarlos y externalizarlos, en favor de la persona. Así pues, la familia surge como un aliado esencial en este esquema, ya que es gracias a la familia que el alumno puede sentirse realmente respaldado para animarse a experimentar, dar a conocer y manifestar aquello que sus capacidades $e$ intereses tienen para generar (Tonucci, 2007).
De otro lado, el Ministerio de Educación (2015), por medio de su portal de Estadística de la calidad educativa, brinda un dato sumamente interesante a ser tomado en consideración: la esperanza de vida escolar (número de años), referida al número de años que puede transcurrir entre la educación básica superior y la educación superior, aquí en el Perú es de 13,8 años, lo cual recuerda cuán necesario es que los alumnos se encuentren guiados y orientados durante todo ese periodo, para que así, puedan lograr desplegar sus capacidades y potenciales recursos.

Es en esa misma línea donde conviene recordar que, educación y orientación van de la mano. Esto resulta fundamental pues la educación necesita que el alumno explore, pregunte, quiera saber más, experimente, busque nuevas alternativas, se nutra de lo que acontece en el entorno, arriesgue al momento de dar a conocer sus opiniones, todo en el marco de una cultura de diálogo y respeto por los involucrados en este proceso creador. Si el ambiente educativo puede alcanzar esto, será mucho más accesible lograr que la orientación cumpla aquello para lo que fue creada: ayudar desde el asesoramiento, abordando y previniendo dificultades en el desarrollo integral de las personas. Otro punto importante a destacar es el rol que ocupan los adultos, pues son ellos quienes acompañan el proceso maduracional de las generaciones venideras, de ahí que resulte básico que estos adultos ofrezcan el bagaje cultural, experiencial y personal que han ido acumulando a través de sus vidas, pues es por medio de esas experiencias vividas, retos asumidos, desafíos superados y cuestionamientos resueltos que el adulto brinda, al joven alumno, la oportunidad de potenciar lo suyo propio (Tonucci, 2007).

\section{Metodología}

Para la identificación de los documentos que compondrían el artículo, en los meses de mayo y junio del 2019, se procedió a consultar las siguientes bases de datos: APA Psycnet, E - Libro, Dialnet, Ebsco, Google Académico y Psicodoc. Adicional a ello, existieron otras fuentes que resultaron de suma utilidad para constituir la estructura y los contenidos del artículo. Estas otras fuentes están conformadas por libros de texto, pertenecientes a autores especialistas en temas 
referidos a la educación y la orientación que esta requiere para con sus alumnos, estadísticas $e$ informes elaborados por el Ministerio de Educación del Perú, entre otros.

Dentro de las temáticas que abordan las bases $\mathrm{de}$ datos previamente señaladas, se realizó una búsqueda de contenidos bibliográficos relacionados con la educación, la orientación educativa, el desarrollo integral de la persona, la autonomía en el ámbito educativo, etc. La búsqueda se delimitó de tal manera que, se pudiese evitar -o cuando menos, disminuir- el número de documentos accesitarios.

Otro de los criterios a considerarse, al momento de llevar a cabo la búsqueda de información, ha sido el contenido teórico que brindaban los diversos autores. Es decir, considerar cuáles eran sus fuentes de origen y así, poder abstenerse de redundar en información o en autores previamente citados.

Por último, se procedió a agrupar la información considerando contenidos teóricos semejantes, temporalidad de los artículos encontrados, así como datos que pudieran ser ilustrativos para estructurar lo que la orientación educativa tiene para ofrecer, considerando lo que acontece en la actualidad.

\section{Desarrollo}

\section{La orientación educativa}

Cuando nos referimos a la orientación, caemos en la cuenta que esta hace referencia a un sentido de ayuda. Es así como, la orientación resulta ser un proceso, por su carácter gradual y sistematizado, en el que las personas reciben guía para abordar posibles dificultades que pudieran presentarse en los distintos ámbitos de su vida: emocional, social, educativo, profesional, social, etc. Así también, cabe destacar que, dicha orientación puede estar presente en las distintas etapas del desarrollo humano, debido al carácter dinámico y evolutivo que poseemos todas las personas (Álvarez y Bisquerra, 2018).

La orientación educativa tiene por tarea buscar soluciones a problemas que pudiesen interferir con el desempeño de los estudiantes. Para esto, la orientación pone en marcha acciones que permitan frenar el avance de dificultades. Tales acciones se orientan a la implementación de programas que abordan temáticas referidas a la motivación hacia el estudio, la autoestima y el uso de técnicas para un mejor aprovechamiento del aprendizaje (Velasco, 2006). Esa orientación educativa es concebida como un proceso de ayuda. Dicho proceso se lleva a cabo por medio del acompañamiento que los orientadores realizan a todo el alumnado, docentes y familias, dentro de una comunidad educativa. Este acompañamiento busca fomentar el desarrollo integral de los distintos miembros de dicha comunidad (Álvarez y Bisquerra, 2018).

La orientación educativa, por medio de la mediación, permite la promoción de potencialidades en los receptores de dicha orientación. El desarrollo de sus capacidades permite un mayor crecimiento personal que responda a los retos educativos que le son planteados al estudiante, dentro del ámbito educativo en el cual se encuentre inserto. Dentro de lo amplia que puede ser la orientación educativa, destacan dos puntos a considerar en procesos de esta índole: luego de la familia, el ámbito educativo es un área clave para poder conocer mucho más acerca de sus estudiantes. El otro punto a considerar es el vínculo que se establece entre el orientador y el orientado; siendo la personalidad del orientado un punto importante a considerar en todo el proceso, esto debido a que las aptitudes que posea el orientado forman parte de su personalidad, de ahí que corresponde ver al orientado como un todo, con aptitudes, rasgos de personalidad y disposición para el proceso de orientación educativa. Ya en la universidad puede creerse que la orientación educativa está de más, porque los estudiantes son jóvenes en proceso de formación profesional y no hay nada más en lo cual guiarlos; pues esta idea resulta errada, ya que la universidad es solo un peldaño más en el desarrollo educativo $e$ integral de la persona, de ahí que se requiera de acompañamiento, guía y orientación para que este tránsito sea exitoso y contribuya al desarrollo integral de la persona (Torres y Torres, 2018).

Uno de los propósitos de la orientación educativa es su aporte al rendimiento de los estudiantes. El rendimiento académico es una valoración del desempeño del estudiante en distintos momentos del curso, a fin de poder contar con criterios objetivos, medibles y comprobables. Es en esa 
misma línea que, la orientación educativa asume una visión amplia sobre el rendimiento académico, pues lo ve como 'parte del' proceso; el rendimiento no es un mero indicador numérico, sino que forma parte del proceso de aprendizaje, el cual se articula con el desempeño del alumno (Velasco, 2006).

La ayuda que se brinda está basada en principios científicos y filosóficos, sobre la base de los cuales los profesionales orientadores hacen uso de estrategias para llevar a cabo una intervención continuada a lo largo de toda la vida educativa de los miembros que componen dicho ámbito. Un punto clave a destacar aquí es la necesidad de que exista cooperación constante entre todos los miembros implicados, tales como: profesores, tutores, orientadores, familias, alumnos, etc. (Álvarez y Bisquerra, 2018).

Resulta esencial incidir en que los orientadores educativos propongan cambios en la visión que se tiene del rendimiento académico. Limitar al estudiante a un puntaje $y$ clasificarlo en categorías arbitrarias puede ir en contra de lo que hoy, como sociedad, nos venimos planteando: la búsqueda de espacios donde los jóvenes puedan desarrollar su autonomía (Velasco, 2006).

Conviene enfatizar que la orientación es un proceso continuo, el cual requiere ser sostenido a lo largo del tiempo, como pieza clave dentro de todo el proceso educativo. Dado que lo que se requiere, para el éxito de la orientación educativa, es continuidad, este proceso se sostiene en la responsabilidad de todos quienes participan de la formación educativa. Adicional a ello, conviene destacar que, la orientación educativa no se limita a trabajar, únicamente, con quienes presenten dificultades de cualquier índole. Caso contrario, la naturaleza de la orientación educativa busca la promoción del desarrollo personal en sus distintos aspectos (Álvarez y Bisquerra, 2018).

Quizás hoy más que en otros tiempos, la tecnología ha cobrado un rol protagónico del cual resulta difícil no formar parte. Las tecnologías de la información y comunicación (TIC) se encuentran insertas dentro del sistema educativo. Es así como, la orientación educativa también pasa a requerir adaptaciones e implementaciones, con el fin de mantenerse a la vanguardia de dichas innovaciones. Gracias a la incorporación de las TIC, ahora es posible ampliar el marco de ejecución de la acción orientadora, ya que aún fuera del sistema educativo, las personas pueden acceder a la guía y el apoyo de los orientadores (Fernández, Nogueira y Couce, 2013).

Asimismo, resulta útil señalar que, considerando los posibles escenarios, la orientación educativa es capaz de atender primordialmente algunos aspectos, pues vienen a ser sus principales áreas de intervención: educativos, vocacionales, personales, emocionales, entre otros. Eso sí, conviene destacar que lo que distingue a la orientación es la integración de los aspectos previamente señalados, en una acción sistematizada (Álvarez y Bisquerra, 2018).

Dentro de los cambios que vivencia la orientación educativa, resulta esencial destacar que los orientadores cuentan con nuevas demandas, de parte del entorno educativo, tales como las TIC, que requieren el uso de herramientas $y$ el despliegue de estrategias que permitan acoger a un mayor número de personas que requieren orientación. Entre los canales que han sido posibles de aparecer a raíz de estas implementaciones, tenemos la orientación a distancia, las fuentes de orientación educativa, profesional $y / 0$ vocacional, disponibles en internet, entre otras (Fernández et al., 2013).

La intervención que realiza la orientación educativa trasciende un enfoque intervencionista, pues su propósito busca ir más allá de solucionar posibles dificultades. Su propósito se encuentra encaminado hacia la prevención, el potencial desarrollo que los beneficiarios pudieran alcanzar y la intervención en la comunidad educativa. Así también, una de las finalidades resulta ser la propia capacidad de desarrollarse, gracias a la autorientación, lo que sugiere el desarrollo de la autonomía como un medio para educar la vida propia (Álvarez y Bisquerra, 2018).

La educación tiene por propósito, aportar al desarrollo de las potencialidades y descubrir las capacidades que posee la persona. En tal sentido, resulta pertinente considerar que la orientación educativa contribuye al uso -más eficaz- de herramientas y estrategias que permitan al individuo, cambiar los modos de aproximarse a nuevos modos de pensar (Rosado, 2012). 
Cuando se habla de intervención, desde la orientación educativa, el planteamiento demanda principios científicos y filosóficos que sirvan de sostén para aquellos profesionales que lleven a cabo estrategias, a partir de lo planteado como base teórica. Desde los principios filosóficos se parte de una visión integral del ser humano, el cual requiere de guía y apoyo en los distintos ámbitos de su vida (educativo, profesional, social, afectivo, entre otros). La malla curricular, que compone los temas a abordarse durante el año académico, tiene por propósito dar a conocer a sus alumnos, un panorama general acerca de su entorno circundante. Resulta ser la apertura de una ventana para atisbar el mundo. Y es, precisamente, a través de esa ventana que se busca que el estudiante pueda encontrarse con su propio reflejo. Este reflejo le devolverá la oportunidad de verse a sí mismo, dando pie a conocerse. Es así como se da a notar la contribución de la orientación educativa hacia el currículo académico. Los contenidos educativos (ventana) y la orientación educativa (reflejo) resultan ser complementarios al momento de contribuir al desarrollo integral de la persona (Álvarez y Bisquerra, 2018).

La orientación educativa busca contribuir a la calidad de la educación, pues se alinea con el desarrollo personal, social y emocional de quienes se encuentran insertos en la comunidad educativa. Esta orientación aporta a la calidad de la educación, pues contempla variables socioemocionales y brinda ayuda a quienes requieren afrontar distintas situaciones que pudieran presentarse (Monge, 2009).

Entonces pues, la orientación educativa resulta ser un proceso de ayuda, gracias al cual se puede intervenir en distintas áreas, entre las cuales tenemos: orientación para la carrera profesional, orientación en los procesos de enseñanza aprendizaje, diversidad, prevención y desarrollo de habilidades personales. Cada área cuenta con características propias y específicas. Ahora bien, lo que le brinda ese carácter integrador al concepto de orientación educativa es la relación existente entre sus distintas áreas, su sentido multidisciplinario (Álvarez y Bisquerra, 2018).

Los nuevos escenarios educativos demandan el empleo de nuevas estrategias para orientar a los estudiantes. Adicional a ello, la orientación educativa incorpora una perspectiva preventiva y proactiva, que prevea los posibles problemas que pudieran acontecer (Monge, 2009).

Por otro lado, quienes llevan a cabo el proceso de orientación educativa son profesionales formados como tales, como orientadores. Recordemos también que, la orientación es un proceso, no una persona. Por ello, conviene considerar que los orientadores también vienen a ser los tutores, profesores e, incluso, la familia (Álvarez y Bisquerra, 2018).

\section{Características del orientado, en la adolescencia}

La adolescencia es un momento trascendental en la vida de todas las personas, pues anuncia el cierre de una etapa y es el inicio que dará pie a una posterior adultez. El cambio es una de las palabras que mejor describe esta etapa, pues lo que era válido y podía dar resultado en la infancia y niñez, no necesariamente será de utilidad en esta nueva etapa. El joven tendrá que buscar nuevas estrategias que le permitan integrarse con éxito a la sociedad, ahora con mayor autonomía y responsabilidad sobre lo que se hace (Moreno, 2007).

Si hay algo que caracteriza a la adolescencia es que no se la pueda "caracterizar". Esta etapa se encuentra dominada por el cambio y la necesidad de encajar que asumen sus protagonistas, debemos recordar que se haya ligada al contexto cultural y social en el que se encuentra. Lo cultural y lo social no se mantienen estáticos, sino que, por el contrario, están fuertemente ligados a variaciones que dependerán de los sucesos que se den en el contexto que viva el adolescente. La adolescencia que tuvimos no se compara a la adolescencia que hoy en día viven los jóvenes, rodeados de un bombardeo constante de información y aspirando a mantenerse a la vanguardia en redes sociales y tecnología de última generación (Funes, 2010).

Un aspecto que cobra fuerza en esta etapa es el plano social. El entorno y su opinión son lo más importante para el adolescente. Se deja de lado la influencia parental para priorizar al grupo de amistades, quienes marcarán la pauta en las conductas y la imagen que el adolescente presentará hacia el exterior (Moreno, 2007). 
En esta línea hemos podido caer en la cuenta de que los conocimientos son útiles. Sin embargo, no son lo único que la persona necesita en su paso por los diferentes niveles académicos que asume. La educación requiere de otros elementos que contribuirán a que la inteligencia sea encausada de modo positivo y en beneficio de la sociedad que conformamos. Para lograr esto, se requiere de una educación en valores que permita a los jóvenes conocer las ventajas de poder llegar a formar parte de una sociedad productiva, en la cual ellos sean responsables de hacer su parte en pro de dar soluciones a los retos que se nos plantean. La convivencia en los ámbitos educativos crea el espacio pertinente para llevar a cabo el aprendizaje de valores (Pérez, 2009).

En esta etapa es fundamental que el joven llegue a desarrollar un conjunto de valores y una ética que oriente su conducta. Esto se logra gracias a los distintos entornos de los cuales forma parte el adolescente: la familia, las amistades, el contexto en el que se encuentra implicado, la realidad nacional que atraviesa, entre otros. La meta que se espera alcanzar, al culminar la etapa de la adolescencia, es que los jóvenes sean capaces de definir sus valores según los principios escogidos por sí mismo, sin considerar la presión que pudieran ejercer las figuras de autoridad o las normas (Moreno, 2007).

Por otra parte, la educación ha experimentado grandes cambios que la alejan cada vez más de las posturas tradicionales en las que el estudiante es un mero ente pasivo, receptor de la información que se le otorga. La educación en valores es posible porque los valores son elegibles y realizables, dependiendo de lo que el sujeto busque alcanzar. Por otro lado, es preciso que recordemos cuál es la situación actual que hoy nos toca vivir. Nos encontramos en una sociedad cargada de actos violentos, delincuencia, carente de sentido, necesitada de respuestas inmediatas sin considerar los procesos, etc. Este marco abre paso a la siguiente idea: como eduquemos hoy a los profesionales que egresarán mañana es la última carta que tenemos por jugar en esta partida. La existencia de una sociedad pacífica no es una utopía, lo que se requiere es tomar conciencia de que la sociedad en la que hoy vivimos es sumamente individualista, donde los valores morales son entretenidos al momento de leerlos, pero no al momento de ponerlos en práctica. La abstracción no nos resulta de mucha utilidad, es por ello que se requiere de contenidos más precisos que favorezcan la aplicación de tales valores (Pérez, 2009).

La tarea esencial de la educación, según nuestra concepción, es formar a la persona. Esa formación considerar proveer al individuo de recursos que le permitan desarrollarse integralmente. La educación universitaria, la cual se encarga de formar a quienes serán los futuros profesionales que pasarán a guiar nuestra sociedad, también debe contar con una enseñanza que provea de valores a los estudiantes, con el fin de que ejerzan su profesión guiados por la ética y por el respeto que han de mantener ante el trabajo que realicen (Benítez, 2009).

La educación en valores no solo le concierne a la educación secundaria o a los cursos de Cívica (secundaria) o Filosofía (secundaria y/o universidad), lo que se busca es que todos los educadores asuman su parte en el proceso de enseñanza $y$, desde su cátedra, propongan actividades que estimulen el uso de valores y promuevan el desarrollo de un criterio donde la ética ocupe el primer lugar (Benítez, 2009). No es posible que desliguemos la enseñanza de valores de la educación, pero es prudente considerar que estos no se aprenden como otros temas. Para enseñar valores es necesario que las actitudes que el docente y el orientador afronten vayan acordes con lo que quieren transmitir. $\mathrm{Si}$ hubiera una incongruencia entre su actitud y lo que está enseñando, los estudiantes percibirán aquello y será en vano todo lo que se les quiera enseñar (Rodríguez, 2012).

\section{Modelos de intervención en la orientación educativa}

Los modelos de intervención son las destrezas a emplearse para obtener los resultados previamente trazados. Con el pasar del tiempo, han ido haciendo su aparición distintos modelos que conviene, el orientador conozca. Las investigaciones realizadas a partir de la implementación de dichos modelos han permitido conocer su nivel de eficiencia. Si bien hay muchos tipos de modelos, conviene centrarse en tres de ellos, los cuales resultan ser básicos para el abordaje desde la orientación educativa (Álvarez y Bisquerra, 2018). 
Una vez insertos en el proceso de orientación, corresponde que el orientador-como agente clave en dicha relación- ponga en práctica actitudes consideradas básicas para el éxito del abordaje: aceptación y comprensión. La aceptación, entendida como la consideración cálida de parte de quien está escuchando aquello que vengo a contarle. Por su parte, la comprensión es un proceso de participación mutua en la cual se desarrollan los temas de interés para quien acude a la orientación (Santana, 2009).

El primero de ellos es el modelo clínico, también conocido como counseling. Dicho enfoque se caracteriza por emplear la técnica de la entrevista personal, por lo que la atención resulta ser individualizada. El modelo de programas, por su parte, parte de un enfoque preventivo, pues busca adelantarse a las dificultades, prevenir que estas surjan y promueve el desarrollo de la persona, en sus distintos ámbitos. Con respecto al modelo de consulta, llamado también asesoramiento, el objetivo es promover la consulta colaborativa como premisa básica, pues la propuesta radica en asesorar a los docentes, tutores, familia, institución educativa u otros, con el propósito de finalizar con éxito los programas de orientación (Álvarez y Bisquerra, 2018).

La orientación educativa resulta posible gracias a la armonización de distintos procesos que suceden al interior de esta. Dentro de esa gama de procesos que ocurren, existen tres puntos esenciales a considerar para el éxito de la orientación educativa: proceso, referido a la temporalidad de la orientación; entorno, el cual otorga significado a los eventos que ocurren dentro de sí y permite circunscribir las experiencias a un determinado espacio y tiempo; por último, la prevención, orientada al carácter anticipatorio que poseemos las personas para asumir estrategias que nos permitan prever ante escenarios desfavorables, prever dentro de la orientación educativa es sinónimo de afianzar conocimiento, actitudes, cualidades, destrezas y demás herramientas que nos permitan minimizar amenazas y salir airosos de ellas. Por otro lado, el rol que cumple el orientador busca escuchar y ayudar al orientado en su propio proceso de autodescubrimiento para aportar a la realización de su proyecto personal, tanto educativo como vocacional (Izurieta, Laura y Zabaleta, 2018).

\section{Áreas de intervención en la orientación educativa}

Durante la década de los sesenta comenzaron a surgir modelos de intervención que buscaban asesorar a las personas, desde un enfoque preventivo, con el propósito de psicoeducar. Es desde estos planteamientos, que comienzan a surgir propuestas, previamente no contempladas, tales como: desarrollo de habilidades sociales, prevención de consumo de sustancias, educación para el cuidado de la propia salud, orientación para el desarrollo del ciclo vital, etc. Por ello, conviene considerar el siguiente orden para abordar las distintas áreas de intervención que puede contemplar la orientación educativa: orientación para el proceso de enseñanza aprendizaje, educación inclusiva, orientación profesional y orientación para la prevención de dificultades y el desarrollo integral de la persona (Álvarez y Bisquerra, 2018).

Dentro de los ámbitos que puede abordar la orientación educativa, resulta importante destacar la orientación centrada en el orientado, pues busca comprender el problema que aqueja al consultante y procura dar con recursos o alternativas para solucionar la dificultad; la orientación centrada en los vínculos del orientado, es decir, abordar dificultades que pudiesen existir entre distintos miembros insertos dentro del sistema educativo; orientación centrada en el programa, pues existen temas transversales al ciclo vital y conviene abordarlos, sobre todo, en un sentido preventivo (Santana, 2009).

Así también, resulta importante señalar que las áreas previamente mencionadas se encuentran vinculadas entre sí. Es gracias a esa conexión que, precisamente, la orientación educativa posee este carácter integrador. Tal es así que, suele suceder, que cuando el orientador realiza intervenciones, no le es posible intervenir solo en un área determinada pues entre todas existe un nexo que las hermana. Esto quiere decir que el orientador dirige sus estrategias al individuo, considerándolo como un todo. Deahí, la viabilidad de que un solo programa recoja elementos de las distintas áreas de intervención. Por ejemplo, un programa de orientación educativa que cuente con elementos para potenciar la enseñanza y el aprendizaje, lo cual contribuye a la orientación 
profesional, mediante el uso de estrategias para atender a la diversidad, aproximándose a una cultura inclusiva en la cual, la prevención y el desarrollo integral contribuyan al desarrollo de la autonomía en los beneficiarios de dicha iniciativa (Álvarez y Bisquerra, 2018).

Uno de los ejes esenciales del proceso de orientación educativa es la oportunidad de formar vínculos entre el orientador y el orientado. Estos vínculos tienen el propósito de fortalecer la alianza entre ambas partes y así, dejar huella en el orientado. Entiéndase que esta huella se refiere a que el estudiante aprenderá a desarrollar autonomía al momento de aproximarse a nuevos ámbitos educativos, en los cuales le serán de utilidad la autorregulación al momento de determinar qué estrategias le resulten más eficaces para abordar tal o cual tarea; la autorregulación también será útil en el ámbito de las emociones, para poder saber reconocerlas y cómo emplearlas en el momento oportuno, por ejemplo: reconocer cuando una tarea es demandante y de qué herramientas hacer uso para sobrellevarla con éxito, saber cuándo defender una postura y cuándo es prudente mostrar apertura para recibir nuevos puntos de vista y actuar en base a ellos, con la convicción del caso (Daura, 2017).

\section{Contextos de intervención en la orientación educativa}

Continuando con Álvarez y Bisquerra (2018), el marco donde se llevan a cabo las intervenciones se adecúa al momento de la vida por el cual está transitando la persona que va a recibir la orientación. El contexto está dado por las circunstancias, es el orientador quien, por medio de las estrategias que posee, apoyará al orientado a poder desenvolverse en dicho entorno. Por ello, conviene recordar que, el orientado está inserto en el sistema educativo formal.

En el proceso de orientación educativa, los alumnos requieren cumplir un papel activo. En el día a día, las personas sorteamos dificultades y ello nos impulsa a hacer uso de estrategias que nos permitan resolverlas y afrontarlas. Ese, resulta ser un claro ejemplo de las estrategias que ya se ejecutan con el fin resolver lo que se va presentando (Tapia, 2012).
Al referirnos a la educación formal, se puede distinguir niveles dentro de ella, niveles tales como: educación inicial, primaria, secundaria y superior. Cada nivel cuenta con sus propias demandas y exigencias y, por supuesto, cada uno de ellos posee características propias que se requiere considerar al momento de poner en marcha acciones orientadoras (Álvarez y Bisquerra, 2018).

El papel activo que desempeñan los orientados, dentro de la orientación educativa, comprende las siguientes implicaciones: resulta prioritario determinar cuáles son los supuestos que afronta el individuo en el sistema educativo y el entorno permite conocer cuán viable es afrontar los desafíos que el entorno educativo propone (Tapia, 2012).

Quienes ejecutan la orientación educativa son un equipo multidisciplinario, un equipo que posee características y habilidades, las cuales pasan a ser herramientas clave para guiar y ayudar al alumno, aun cuando esté no se encuentre inmerso en dificultades. Tal es así que, la formación de los orientadores puede ser variada y amplia. Entre los profesionales orientadores, podemos encontrar a psicólogos, educadores y psicopedagogos. Adicional a ello, los tutores, la plana docente y la familia también pueden participar del proceso de orientación, pues conocen de cerca lo que le atañe al estudiante y pueden tomar acciones al respecto (Álvarez y Bisquerra, 2018).

Finalmente, la orientación educativa es una estrategia formativa que contribuye al mejoramiento de los resultados de aprendizaje obtenidos por los jóvenes y, además, también posibilita su desarrollo integral. En esa misma línea, la orientación educativa es considerada como un valioso recurso asistencial que no puede ser sustituido por mayor carga académica o actualizaciones en la malla, pues la orientación busca adaptarse a las necesidades individuales que cada estudiante trae consigo al proceso, a fin de poder apoyarlos en sus procesos individuales (Gainza, García, Batista y Lahera, 2016).

\section{Necesidad de la orientación educativa}

La orientación educativa surge como una alternativa que complementa el proceso educativo. Resulta necesaria como fuente de apoyo y prevención para la aparición de posibles 
dificultades. Algunos de los puntos que respaldan esta afirmación son la necesidad de todas las personas por tomar decisiones que le permitan entrar en contacto con su vocación. Así también, el incremento del grado de dificultad que existe hoy en día al momento de aproximarse a conocer lo que proponen las distintas profesiones en sus planes de estudio; cada vez hay más especializaciones, cursos, enfoques, modelos, teorías y modos de aproximarse a estos, lo que puede generar que los jóvenes requieran de guía para poder organizar los datos requeridos para, gracias a ello, comenzar a decidir qué ruta desean tomar. Sumado a esto, el desarrollo personal requiere de apoyarse en autoconocimiento $y$ autoestima, pues ambos permiten el crecimiento de la persona en los distintos ámbitos de su vida; además, gracias a este autodescubrimiento es que el individuo puede notar la presencia de posibles dificultades y, si así lo desea, buscar ayuda (Álvarez y Bisquerra, 2018).

Así también, la actitud de los orientadores, ante el proceso de orientación educativa, resulta ser vital al momento de la intervención. Esto debido a que, las demandas de los miembros del sistema educativo son cotidianas y demandan, de parte de los orientadores, apertura y flexibilidad para poder acoger y sobrellevar su labor (Vuelvas, 2010).

De otro lado, los cambios en la tecnología resultan ser constantes y demandan, de parte del receptor, una capacidad de adaptabilidad y rápida respuesta a estos, con el fin de poder implementarlos en su día a día. A su vez, existe un compromiso implícito de parte de quienes se encuentran insertos en el sistema educativo, para con la sociedad. Esto debido a que, el propósito de la orientación educativa es contribuir al desarrollo de todos los talentos posibles que puede alcanzar el individuo (Álvarez y Bisquerra, 2018).

\section{Discusión}

Resulta evidente darnos cuenta de cuánto terreno ha ido ganando la orientación educativa en los últimos años, pues es bien sabido que las necesidades por acceder a un proceso de introspección, propio y personal se han incrementado. Basta con echar un vistazo a la juventud actual para comprender cuán necesitados se encuentran por hallar guía $u$ orientación que les permita esbozar un proyecto de vida centrado en sus verdaderos intereses, previamente balanceados con las oportunidades de acceso con las que cuentan en el plano educativo $\mathrm{y}$, posteriormente, laboral.

La orientación educativa se halla inserta en el proceso educativo. Esto es posible gracias a la función orientadora de quienes se desempeñan como educadores. La orientación contribuye a gestionar recursos: recursos personales, aptitudinales y actitudinales, los cuales son esenciales para responder a las necesidades que surgen en la comunidad educativa. Adicional a ello, la orientación también contribuye al proceso de enseñanza-aprendizaje, ya que propicia mejoras en la comunicación, busca la autonomía del estudiante al momento de aproximarse a nuevos conocimientos y otorga libertad para que el estudiante encuentre sus propias rutas para cimentar nuevos aprendizajes.

Ahora bien, entonces ¿̇cuál sería el propósito de la orientación educativa? Su objetivo es abrir el camino para posibilitar el desarrollo de los talentos potenciales con los que contamos todas las personas. En síntesis, la orientación es el desarrollo humano de la persona.

Aunado a la orientación, existe una pieza clave para que el engranaje de este pueda prosperar: el enfoque centrado en la persona, entendido como la oportunidad que existe de que el otro sea mirado como un semejante disponible no solo para resolver sus problemas, sino para transformar su vida, si así lo desea. Gracias a esta perspectiva, se concluye que nadie es poseedor de la verdad, que cada persona, cuando emite juicios y opiniones, los lleva a cabo desde su propio y personal modo de aprehender la experiencia. Por ello, ésta requiere de ser aceptada en su propia expresión (Tapia, 2012).

Por su parte, la escucha empática hace referencia a la capacidad de entender, comprender y responder a la experiencia única que otorga la otra parte, es decir, comprender desde el marco de referencia del otro. En este proceso entran a tallar los aspectos emocionales y cognitivos, pues tiene que ver con las emociones y los sentimientos (aspectos emocionales), sumados al significado personal que se le provea (pensamiento-cogniciones). 
Sobre la aceptación, dentro del proceso de orientación, comprender que lo que al otro le pasa es válido para él como experiencia en sí misma, y que este otro es el único que podrá revisarlo y modificarlo si considera que le produce conflictos, sufrimientos o molestias. Es gracias a la aceptación que la persona podrá abrirse a sí misma y a su entorno de una manera más genuina y real.

En cuanto a la orientación educativa, el proceso otorgará la responsabilidad pertinente al orientado, a fin de hacerlo un participante activo de la orientación, promoviendo la aparición de autonomía $e$ independencia. Los profesionales responsables de la orientación necesitan adecuar las técnicas ya existentes, según el caso que se tenga en frente, sus necesidades y su criterio personal. Debido a lo específico de la ejecución, resulta vital que los orientadores cuiden $y$ afinen su principal instrumento de trabajo: su personalidad (Rodríguez, 2012).

Sin embargo, como en todo proceso, existe un craso error que requiere de toda nuestra atención: los orientadores suelen ser entrenados para no 'engancharse' con sus orientados, y se les aconseja permanecer objetivos o, incluso, gentilmente apartados. Es precisamente la habilidad del orientador para comprometerse y compartir el mundo de su consultante lo que determinará su efectividad. Finalmente, es así como queda claro que no es posible crear o modificar 'desde afuera' de la realidad del otro.

\section{Conclusiones}

El concepto de aprendizaje ha ido evolucionando de acuerdo con los requerimientos y necesidades de la época. En el siglo XX se consideraba que el aprendizaje era conseguir que el alumno respondiera a las interrogantes planteadas por el maestro. Sin embargo, ahora, comprendemos que el aprendizaje no es un constructo mecánico y rígido. Por el contrario, este se orienta a desarrollar las múltiples posibilidades con las que cuenta cada aprendiz; para lograr aquello, se vale de diversos recursos que apunten al desarrollo del estudiante en aspectos de diversa índole. De ahí la importancia de promover la orientación educativa como parte del proceso de formación de las personas, como un elemento que contribuye al desarrollo integral del individuo (Álvarez y Bisquerra, 2018).

A lo largo de la historia ha habido muchos autores, quienes desarrollaron teorías, plantearon hipótesis y propusieron definiciones. Todos ellos convergen en un mismo punto: la persona cuenta con un potencial que puede desarrollarse. Para lograr aquello urge replantear la concepción que el estudiante pudiera tener acerca del propósito de aprender pues, si el aprendizaje es visto como un mero intercambio de información a través del cual se aprobarán cursos y se sortearán niveles con el fin de llegar a la meta y ahí, por fin, dejar de lado los conocimientos recibidos, nos encontramos en serias dificultades.

El objetivo de lograr aprender es que el alumno desarrolle su capacidad de pensar, es decir, que lo que reciba del maestro puede serle útil, aún luego de terminado el curso. Los principios del aprendizaje hablan precisamente de eso: de la búsqueda de un sentido, de un propósito, de un fin que contribuya al logro de metas personales, las mismas que se irán trazando en la medida que el estudiante elabore sus propios pensamientos, se nutra de conocimientos y tenga claros los objetivos que quiere para sí mismo.

Es gracias a esta nueva concepción que se tiene del aprendizaje, que logramos posicionar al estudiante en un rol protagónico, un rol que lo empodera y le brinda mayor responsabilidad sobre su propio proceso. Gracias a la guía y el apoyo brindado por el docente, el alumno incorporará los conocimientos como parte de sí mismo y así, logrará una participación activa y comprometida con aquello que recibe en las aulas de clase de parte de compañeros y maestros (Rodríguez, 2012).

Finalmente, se ha de añadir que la orientación educativa abre la puerta de entrada a potenciar el compromiso y esfuerzo de los alumnos para alcanzar sus máximas capacidades, destacarse en sus intereses $y$ habilidades $y$, a partir de ahí, enriquecer su personalidad para brindar aportes y beneficios a la sociedad en la que elija establecerse (Tonucci, 2007). 


\section{REFERENCIAS}

Álvarez, M. y Bisquerra, R. (2018). Orientación educativa: modelos, áreas, estrategias y recursos. Segunda edición. Madrid: Wolters Kluwer. Recuperado de http://ebookcentral.proquest.com/lib/ bibudlimasp/detail.action?docID $=4870912$.

Benítez, L. (2009). Actividades y recursos para educar en valores. Madrid: PPC Editorial.

Daura, F. (2017). Perspectiva temporal de los universitarios: implicaciones para la orientación educativa. Educación y Educadores, 20(3), 403-418. Recuperado de https://educacionyeducadores.unisabana. edu.co/index.php/eye/article/view/6737/4665\#?

Fernández, E., Nogueira, M. y Couce, A. (2013). El uso de las tecnologías de la información y la comunicación en la orientación educativa: explorando la familiaridad y preparación de los profesionales del ámbito en España. Revista Mexicana de Orientación Educativa, 10(24), 45-55. Recuperado de http://web.a.ebscohost.com/ehost/pdfviewer/pdfviewer?vid=6\&sid=80a539b8-4202-46a5-85e8da38ff2be767\%40sessionmgr4006

Funes, J. (2010). Nueve ideas clave: educar en la adolescencia. Barcelona: Editorial GRAÓ.

Gainza, M., García, A., Batista, A. y Lahera, F. (2016). La orientación educativa para la educación de valores éticos en estudiantes preuniversitarios. Didasc@lia: Didáctica y Educación, 7(1), 137-156. Recuperado de http://200.14.53.83/index.php/opuntiabrava/article/view/253/248

Izurieta, R., Laura, M. y Zabaleta, V. (2018). Estrategias de orientación educativa en el caso de alumnos de grado de movilidad estudiantil. Orientación y Sociedad, 18(1/2), 95-129. Recuperado de http://web.a.ebscohost.com/ehost/pdfviewer/pdfviewer?vid=1\&sid=c61bb0c2-23c4-4a5b-a14b24b0f96711ba\%40sessionmgr4007

Ministerio de Educación. (2015). Esperanza de vida escolar (número de años). Lima, Perú: Estadística de la Calidad Educativa. Recuperado de http://escale.minedu.gob. pe/tendencias; jsessionid $=2$ fe4e196c2b38c4facaf4ea23352?p_auth =PTqjojk4\&p_p_ $\mathrm{id}=$ TendenciasActualPortlet_WAR_tendenciasportlet_INSTANCE_90Hs\&p_p_lifecycle $=1 \& \mathrm{p}_{-} \mathrm{p}_{-}$

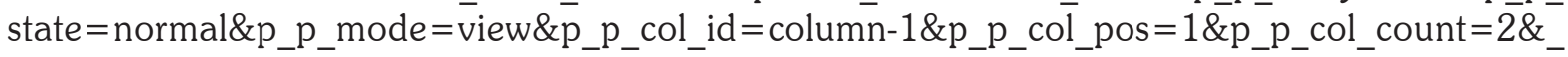
TendenciasActualPortlet_WAR_tendenciasportlet_INSTANCE_90Hs_idCuadro $=201$

Monge, C. (2009). Tutoría y orientación educativa: nuevas competencias. Madrid: Wolters Kluwer.

Moreno, A. (2007). La adolescencia. Barcelona: Editorial UOC.

Pérez, C. (2009). Valores y normas para la convivencia en el aula: programas de intervención educativa. Madrid: Editorial EOS.

Rodríguez, R. (2012). Educación en valores en el ámbito universitario: propuestas y experiencias. Madrid: Narcea, S.A. de Ediciones.

Rosado, A. (2012). Género, orientación educativa y profesional. Revista Mexicana de Orientación Educativa, 9(22), 34-39. Recuperado de http://web.b.ebscohost.com/ehost/pdfviewer/ pdfviewer?vid=3\&sid=68ff81d9-8b81-4005-a839-ccdc70cbdf31\%40pdc-v-sessmgr03

Santana, L. (2009). Orientación educativa e intervención psicopedagógica: cambian los tiempos, cambian las responsabilidades profesionales. Madrid: Pirámide. 
Tapia, J. (2012). Evaluación psicopedagógica y orientación educativa. Madrid: Síntesis.

Tonucci, F. (2007). Cuarenta años con ojos de niño. Barcelona: Editorial GRAÓ.

Torres, Y.y Torres, A. (2018). La labor educativa del gabinete de orientación en el proceso pedagógico de la Universidad de Holguín. Pedagogía Universitaria, 23(1), 51-63. Recuperado de http://web.a.ebscohost. com/ehost/pdfviewer/pdfviewer?vid=1\&sid=da9b28b2-108f-47de-80a1-90ba606c435d\%40sdc-vsessmgr03

Trahtemberg, L. (2014). Desaprender y reaprender: reflexiones sobre la función directiva. Lima: Instituto Apoyo.

Velasco, S. (2006). El rendimiento académico: desde la práctica de la orientación educativa. Revista Mexicana de Orientación Educativa, 4(9), 41-44. Recuperado de http://web.a.ebscohost.com/ehost/ pdfviewer/pdfviewer?vid=3\&sid=80a539b8-4202-46a5-85e8-da38ff2be767\%40sessionmgr4006

Vuelvas, B. (2010). Prácticas y representaciones en orientación educativa. Revista Mexicana de Orientación Educativa, 7(18), 25-33. Recuperado de http://web.b.ebscohost.com/ehost/pdfviewer/ pdfviewer?vid=4\&sid=44637085-2ea5-410d-97eb-688c198c1633\%40sessionmgr101

Fecha de recepción: 19-06-19.

Fecha de aceptación: 30-06-19. 